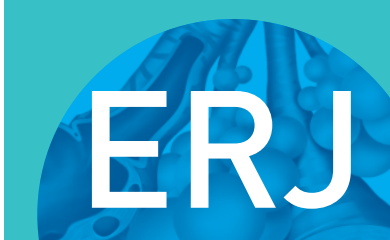

open research

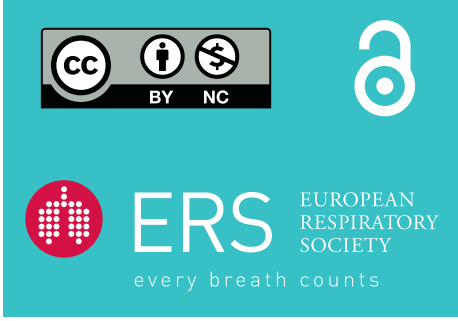

\section{Familial hypersensitivity pneumonitis triggered by Cladosporium herbarum exposure during carpooling}

To the Editor:

Hypersensitivity pneumonitis (HP) is a respiratory disease caused by an inappropriate immune response to environmental antigens affecting the small airways and lung parenchyma. With an incidence of 0.3-1.94 cases per 100000 per year [1,2], HP is the third cause of interstitial lung disease (ILD) [3]. Seven to $17 \%$ of patients with HP report a positive family history for ILD [4, 5], suggesting predisposing genetic factors.

Albeit often difficult to achieve, antigen identification and avoidance is the cornerstone of disease treatment. Whether environmental inquiries have an effect on antigen identification still remains elusive. Regarding potential biomarkers, serum specific antibodies may underpin a diagnosis of HP in an appropriate clinical context [6], but their role is debated, given their presence in antigen-exposed asymptomatic individuals [7]. We report a case of familial HP in two first-degree relatives possessing the promoting HLA-DRB1 ${ }^{\star} 13$ allele in which home inquiry permitted antigen identification (moulds in the family car) and eradication, while specific serum precipitins mirrored the clinical course.

A 25-year-old non-smoking female patient was referred for progressive non-productive cough and shortness of breath over a 2 months course (from June to July), culminating at modified Medical Research Council (mMRC) grade 3 dyspnoea. She had no relevant medical history and was not taking any medication at that time. She had been hospitalised in another centre twice for episodes of acute respiratory failure in the past couple of months, where a working diagnosis of acute asthma exacerbations had been made, leading to the prescription of long-acting $\beta$-agonists, inhaled and oral corticosteroids, followed by a rapid improvement. However, symptoms eventually relapsed after treatment discontinuation. A thorough environmental history could not identify any favouring exposure. At presentation, the patient was tachypnoeic (30 breaths. $\left.\mathrm{min}^{-1}\right)$, tachycardic $\left(118\right.$ beats $\left.\cdot \mathrm{min}^{-1}\right)$ and desaturated at room air $\left(\mathrm{O}_{2}\right.$ saturation $87 \%)$. Arterial blood gas revealed a oxygen tension $\left(P_{\mathrm{aO}_{2}}\right)$ of $60 \mathrm{mmHg}$, a carbon dioxide tension $\left(P_{\mathrm{CO}_{2}}\right)$ of $45 \mathrm{mmHg}$ and a $\mathrm{pH}$ of 7.45. She had mild inflammation in her bloodwork with a C-reactive protein level of $20 \mathrm{mg} \cdot \mathrm{L}^{-1}$ (normal value $<5 \mathrm{mg} \cdot \mathrm{L}^{-1}$ ). The patient was hospitalised and received oxygen supplementation. Chest CT showed bilateral diffuse ground-glass opacities associated with areas of mild air-trapping. Spirometry displayed a restrictive pattern (forced vital capacity (FVC) $44 \%$ of predicted values) associated with a profound alteration of diffusion capacity (25\% of predicted values) (figure 1a). Auto-antibody determination could not find any signs of underlying systemic disease. Broncho-alveolar lavage demonstrated a high lymphocyte count (66\% lymphocytes) and serum precipitins were positive for Cladosporium herbarum (5.8 times the upper limit of normal (ULN), figure 1a). A confident clinical diagnosis of HP was made and a treatment with systemic steroids was started.

The patient reported that her mother, living in the same house, had experienced similar symptoms within the same time frame. Concordant clinical signs, HRCT showing diffuse ground-glass opacities and marked BAL lymphocytosis $(93 \%)$ and inflammation (633 nucleated cells $\left.\mu \mathrm{L}^{-1}\right)$, led to an HP diagnosis, for which we also started oral steroids.

@ERSpublications

This series reports cases of Cladosporium herbarum-related HP due to an uncommon exposure source, illustrating the genetic background underlying HP, and highlighting the role of environmental home inquiry and serum precipitins in diagnosis and follow-up https://bit.ly/ 3hzvE4w

Cite this article as: Planté-Bordeneuve T, Gilbert $\mathrm{O}$, Latinne $\mathrm{D}$, et al. Familial hypersensitivity pneumonitis triggered by Cladosporium herbarum exposure during carpooling. ERJ Open Res 2020; 6: 00233-2020 [https://doi.org/10.1183/23120541.00233-2020].

Copyright $\odot$ ERS 2020. This article is open access and distributed under the terms of the Creative Commons Attribution NonCommercial Licence 4.0. 

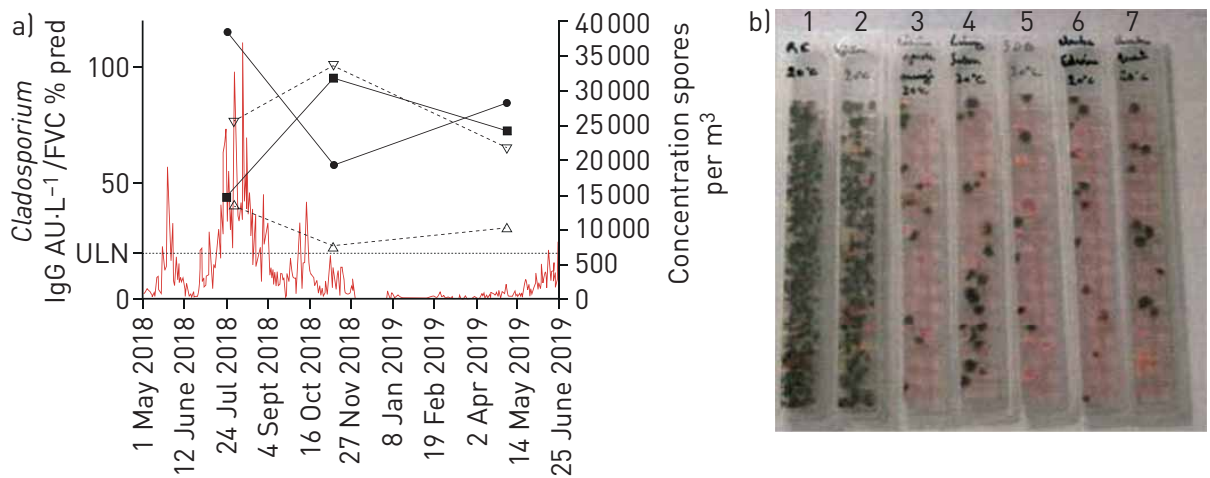

\begin{tabular}{|c|c|c|c|c|c|c|}
\hline $\begin{array}{c}\text { Sample } \\
\text { label }\end{array}$ & $\begin{array}{c}\text { Sampling } \\
\text { place }\end{array}$ & \begin{tabular}{|c|} 
Load \\
CFU per \\
$50 \mathrm{~L}$
\end{tabular} & $\begin{array}{c}\text { Cladosporium } \\
\text { spp. }\end{array}$ & \begin{tabular}{|c|} 
Penicillium \\
spp.
\end{tabular} & \begin{tabular}{|c|} 
Sterile \\
mycelium
\end{tabular} & Yeasts \\
\hline 1 & $\begin{array}{c}\text { External } \\
\text { control }\end{array}$ & $>300$ & $>300$ & $>10$ & $>5$ & \\
\hline 2 & Car & $>300$ & $>300$ & 7 & 5 & 1 \\
\hline 3 & Cupboard & 21 & 10 & 6 & 4 & 1 \\
\hline 4 & $\begin{array}{l}\text { Living } \\
\text { room }\end{array}$ & 31 & 25 & 1 & 1 & 4 \\
\hline 5 & Bathroom & 17 & 7 & 9 & 1 & \\
\hline 6 & $\begin{array}{c}\text { Patient's } \\
\text { room }\end{array}$ & 22 & 12 & 2 & 6 & 2 \\
\hline 7 & $\begin{array}{c}\text { Parents' } \\
\text { room }\end{array}$ & 20 & 12 & 4 & 2 & 2 \\
\hline
\end{tabular}

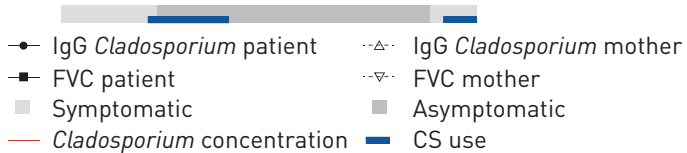

FIGURE 1 a) Evolution of forced vital capacity (FVC) and specific (s)lgG for Cladosporium herbarum for both patients over time. The red line represents Cladosporium spp. outdoor air concentrations as measured by the national aerobiological surveillance network. The upper limit of normal (ULN) for slgG for $C$. herbarum is represented by the dotted line, FVC percentage of the predicted value and slgG levels are shown on the left $y$-axis, while Cladosporium spp. outdoor air concentrations are represented on the right $y$-axis. The clinical course of the patients is displayed underneath, with solid grey bars representing symptomatic periods and blue bars corresponding to corticosteroids intake timings. Upon relapse of the disease, a rise in the outdoor concentrations of Cladosporium spores as well as of the antibody levels is observed. b) Mould culture strips obtained from the ambient air in the patient's environment. The patient's car (sample 2) displayed a very high number of $C$. herbarum colonies. $\mathrm{AU}$ : arbitrary units; CS: corticosteroids.

Despite the absence of a clear exposure at first interrogation, C. herbarum-specific IgG were determined during a visit at our outpatient clinic and also showed supra-normal levels (figure 1a).

A local environmental inquiry was ordered at the patients' home and revealed a high Cladosporium spp. burden in the family car with which they frequently carpooled (figure $1 \mathrm{~b}$ ). The vehicle was removed and under their treatment regimen both rapidly improved their clinical and radiological status and their lung functions. To investigate a possible shared genetic background, we performed HLA typing, revealing the presence of the $\mathrm{DRB}^{\star} 13$ allele in both patients.

In May of the following year, they simultaneously experienced a relapse of their symptoms. Lung function tests were altered (figure 1a) and IgG specific for C. herbarum were again elevated (figure 1a). Both the initial episode and the relapse coincided with seasonal concentration peaks in Cladosporium spp. in the outdoor air (>30000 spores $\cdot \mathrm{m}^{-3}$ in July $2018,>2500$ spores $\cdot \mathrm{m}^{-3}$ in May 2019) according to the measurements of the national aerobiological surveillance network (Sciensano, Belgium). Under medium-dose oral steroid treatment (starting at $16 \mathrm{mg}$ methylprednisone then tapering), both patients experienced a favourable clinical evolution. They did not relapse ever since.

These cases illustrate several areas of uncertainty in HP, including the role of genetic background and the inclusion of environmental inquiries and environment in diagnosis strategy.

The majority of gene polymorphisms linked to HP relate to inflammation (TNF- $\alpha$ ), antigen processing (PSMB8), transport (TAP1) and presentation pathways (MHC II) [8]. Similar to observations in idiopathic pulmonary fibrosis, chronic HP patients also display increased rates of mutations in telomere-related genes [5] as well as in the rs35705950 MUC5B polymorphism [9], suggesting potentially shared pathogenic mechanisms in the development of fibrosis. Additionally, a recent publication has linked HLA-DRB1 ${ }^{\star} 03: 01$ with mortality in HP [10], and one study has specifically analysed the presence of several HLA alleles and TNF polymorphisms in familial HP, reporting increased frequencies of $\mathrm{DRB}^{*} 04: 07, \mathrm{DRB} 1^{\star} 04: 05, \mathrm{DRB} 1^{*} 11: 01, \mathrm{DRB} 1^{*} 13: 01$ and TNF-238 GG in affected individuals [11]. In our case, both patients possessed the $\mathrm{HLA}_{\mathrm{DRB}}{ }^{\star} 13$ allele, in accordance with previous data, further reinforcing this link.

Antigen identification forms one of the pitfalls in HP treatment as it is only achieved in $40 \%$ of cases [12]. Unfortunately, mortality is higher in patients in whom the causative agent cannot be singled out [13]. Specific serum IgG (sIgG) directed towards the offending agents represent a potential diagnostic clue, but are more reflective of exposure than pathogeny, as suggested by the presence of elevated IgG towards harmful antigens in asymptomatic farmers [14] and their low sensitivity [15]. Conversely, the presence of positive sIgG in the context of suspected HP has a strong positive predictive value [6]. Variation of sIgG 
levels makes their interpretation even more complex. Cladosporium herbarum precipitins paralleled disease course in our report, illustrating their possible use as predictive markers. Nonetheless, whether the titre increase preceded the flare, thus reflecting a relapse-predicting value, or developed synchronously, merely indicating re-exposure remains to be determined.

Additionally, further studies are required to evaluate the exact impact of outdoor and indoor air quality, especially regarding fungal spore concentrations on disease course. Currently, no data are available regarding potentially harmful concentrations in the context of HP. Nevertheless, in our case, the elevated Cladosporium burden present in the car may have served as an initial trigger while the mild relapse coincided with elevated outdoor Cladosporium spores levels.

As illustrated by our case, environmental inquiries may allow 1) identification of sources that were not suspected during the patient visit, 2) sampling of antigens and 3) better identification of the contamination source. To our knowledge, only one pilot study has evaluated the potential benefits of this intervention, showing high IgG positive rates in HP patients deemed to have ongoing exposure [16]. The location labelling of the samples allowed for targeted practical advice regarding avoidance, possibly resulting in less drastic and more efficient removal of the source. Regarding our patients, home investigation allowed the detection and eviction of a mould contamination source which would otherwise certainly have been missed, likely leading to milder disease course. Next to these incidental data, prospective trials studying cost-effectiveness and long-term outcome should be performed to substantiate the role of those surveys.

Thomas Planté-Bordeneuve $\odot^{1}$, Olivier Gilbert $^{2}$, Dominique Latinne ${ }^{3}$, Nicolas Bruffaerts ${ }^{4}$, Benoit Ghaye $^{5}$ and Antoine Froidure $\oplus^{1}$

${ }^{1}$ Pneumology Dept, Cliniques universitaires Saint-Luc, Brussels, Belgium. ${ }^{2}$ Pneumology Dept, Centre Hospitalier Universitaire de Charleroi, Charleroi, Belgium. ${ }^{3}$ Dept of Clinical Biology, Cliniques universitaires Saint-Luc, Brussels, Belgium. ${ }^{4}$ Mycology and Aerobiology service, Sciensano, Brussels, Belgium. ${ }^{5}$ Radiology Dept, Cliniques universitaires Saint-Luc, Brussels, Belgium.

Correspondence: Antoine Froidure, Service de pneumologie, Cliniques universitaires Saint-Luc, Avenue Hippocrate 10, 1200 Brussels, Belgium. E-mail: antoine.froidure@uclouvain.be

Received: 2 June 2020 | Accepted after revision: 10 June 2020

Conflict of interest: None declared.

\section{References}

1 Hyldgaard C, Hilberg O, Muller A, et al. A cohort study of interstitial lung diseases in central Denmark. Respir Med 2014; 108: 793-799.

2 Fernandez Perez ER, Kong AM, Raimundo K, et al. Epidemiology of hypersensitivity pneumonitis among an insured population in the United States: a claims-based cohort analysis. Ann Am Thorac Soc 2018; 15: 460-469.

3 Biglia C, Ghaye B, Reychler G, et al. Multidisciplinary management of interstitial lung diseases: a real-life study. Sarcoidosis Vasc Diffuse Lung Dis 2019; 36: 108-115.

4 Okamoto T, Miyazaki Y, Tomita M, et al. A familial history of pulmonary fibrosis in patients with chronic hypersensitivity pneumonitis. Respiration 2013; 85: 384-390.

5 Ley B, Torgerson DG, Oldham JM, et al. Rare protein-altering telomere-related gene variants in patients with chronic hypersensitivity pneumonitis. Am J Respir Crit Care Med 2019; 200: 1154-1163.

6 Lacasse Y, Selman M, Costabel U, et al. Clinical diagnosis of hypersensitivity pneumonitis. Am J Respir Crit Care Med 2003; 168: 952-958.

7 Cormier Y, Letourneau L, Racine G. Significance of precipitins and asymptomatic lymphocytic alveolitis: a 20-yr follow-up. Eur Respir J 2004; 23: 523-525.

8 Vasakova M, Selman M, Morell F, et al. Hypersensitivity pneumonitis: current concepts of pathogenesis and potential targets for treatment. Am J Respir Crit Care Med 2019; 200: 301-308.

9 Ley B, Newton CA, Arnould I, et al. The MUC5B promoter polymorphism and telomere length in patients with chronic hypersensitivity pneumonitis: an observational cohort-control study. Lancet Respir Med 2017; 5: 639-647.

10 Buendía-Roldán I, Santiago-Ruiz L, Pérez-Rubio G, et al. A major genetic determinant of autoimmune diseases is associated with the presence of autoantibodies in hypersensitivity pneumonitis. Eur Respir J 2020; in press [https://doi.org/10.1183/13993003.01380-2019].

11 Falfán-Valencia R, Camarena Á, Pineda CL, et al. Genetic susceptibility to multicase hypersensitivity pneumonitis is associated with the TNF-238 GG genotype of the promoter region and HLA-DRB1 ${ }^{\star} 04$ bearing HLA haplotypes. Respir Med 2014; 108: 211-217.

12 Ryerson CJ, Vittinghoff E, Ley B, et al. Predicting survival across chronic interstitial lung disease: the ILD-GAP model. Chest 2014; 145: 723-728.

13 Fernández Pérez ER, Swigris JJ, Forssén AV, et al. Identifying an inciting antigen is associated with improved survival in patients with chronic hypersensitivity pneumonitis. Chest 2013; 144: 1644-1651.

14 Cormier Y, Bélanger J, Beaudoin J, et al. Abnormal bronchoalveolar lavage in asymptomatic dairy farmers. Am Rev Respir Dis 1984; 130: 1046-1049. 
15 Kelly B, Moua T. Utility of circulating antibody serology in the diagnosis of hypersensitivity pneumonitis. Chest 2017; 152: A823.

16 Millerick-May ML, Mulks MH, Gerlach J, et al. Hypersensitivity pneumonitis and antigen identification - an alternate approach. Respir Med 2016; 112: 97-105. 